\title{
Thermal-Mechanical-Hydrological-Chemical Responses in the Single Heater Test at the ESF
}

\author{
W. Lin, S. Blair, M. Buettner, T. Buscheck, W. Daily, G. Gdowski, W. Glassley, K. Lee, \\ A. Ramirez, D. Ruddle, J. Roberts, S. Trettenero, D. Watwood and R. Carlson
}

This paper was prepared for submittal to the NYRocks 97 Conference, 36th US. Rock Mechanics Symposium New York, $N Y$

June 29-July 2, 1997

This is a preprint of a paper intended for publication in a journal or proceedings. Sincechanges may be made before publication, this preprint is made available with the understanding that it will not be cited or reproduced without the permission of the author. 


\section{DISCLAIMER}

This document was prepared as an account of work sponsored by an agency of the United States Government. Neither the United States Government nor the University of California nor any of their employees, makes any warranty, express or implied, or assumes any legal liability or responsibility for the accuracy, completeness, or usefulness of any information, apparatus, product, or process

disclosed, or represents that its use would not infringe privately owned rights. Reference herein to any specific commercial product, process, or service by trade name, trademark, manufacturer, or otherwise, does not necessarily constitute or imply its endorsement, recommendation, or favoring by the United States Government or the University of California. The views and opinions of authors expressed herein do not necessarily state or reflect those of the United States Government or the University of California, and shall not be used for advertising or product endorsement purposes. 


\title{
Thermal-mechanical-hydrological-chemical responses in the Single Heater Test at the ESF
}

by

\author{
Wunan Lin, Steve Blair, Mike Buettner, Tom Buscheck, William Daily, Greg Gdowski, William \\ Glassley, Ken Lee, Abe Ramirez, Dave Ruddle, Jeff Roberts, Stan Trettenero, and Don Watwood \\ at Lawrence Livermore National Laboratory, Livermore, CA 94550 \\ and \\ Richard Carlson at Woodward-Clyde Federal Services, Las Vegas, NV
}

\section{Abstract}

The Single Heater Test (SHT) is conducted in the Exploratory Studies Facility (ESF) to study the thermal-mechanical responses of the rock mass. A set of boreholes were drilled in the test region for conducting a scoping test of the coupled thermal-mechanical-hydrological-chemical (TMHC) processes. The holes for the TMHC tests include electrical resistivity tomography (ERT), neutron logging/temperature, hydrological, and optical multiple point borehole extensometers. A 4-kW heater was installed in the heater hole, and was energized on August 26, 1996. Some observed movements of the water around the heater are associated with a possible dry-out region near the heater. The water that has been moved is more dilute than the in situ ground water, except for the concentration of $\mathrm{Ca}$. This indicates that fractures are the major water pathways, and the displaced water may have reached an equilibrium with carbonate minerals on the fracture surfaces. No mechanical-hydrological coupling has been observed. The tests are ongoing, and more data will be collected and analyzed.

\section{Introduction}

Yucca Mountain Site Characterization Project (YMP) studies the feasibility that Yucca Mountain can be used as a potential repository for high-level nuclear wastes. The study includes prediction of the quantity and quality of water in the near-field of a repository. The quality and quantity of water in the near-field of a repository will affect the release rate of radioactive nuclides from waste packages, and the transport of the nuclides through the rock mass adjacent to the waste package. The radioactive decay heat from the high-level nuclear waste may increase the temperature in the rock mass so that coupled thermal-mechanical-hydrological-chemical (TMHC) processes may exist in the originally partially saturated Topopah Spring tuff, which is the host rock for the potential repository in Yucca Mountain. Modeling the coupled TMHC processes is necessary in order to predict the quantity and quality of water in the near-field environment for the entire life span of a repository, which is tens of thousands of years. In situ thermal tests are required to build up the confidence level of the coupled TMHC models. 
The Single Heater Test (SHT) is one of the in situ thermal tests being conducted in the Exploratory Studies Facility (ESF) in Yucca Mountain to enhance the understanding of the coupled TMHC processes. The primary objective of the SHT is to investigate the thermal-mechanical responses of the Topopah Spring tuff in Yucca Mountain[1]. The scale and the configuration of the SHT are not appropriate for a complete full-scale study of the coupled TMHC processes. However, it is used as a shake-down for in situ testing of the coupled TMHC processes. The heater of the SHT was energized to a full power of about $4 \mathrm{~kW}$ on August 26, 1996. The fullpower heating is planned to continue for at least 9 months. Then the heater will be turned off to start a cool-down phase of the test. This paper briefly describes the SHT, and reports the progress of the thermal-mechanical-hydrological-chemical part of the SHT.

\section{Description of the SHT}

The SHT is located off the Observation Drift at about $40 \mathrm{~m}$ from the Main Tunnel of the ESF, at about $2.8 \mathrm{~km}$ from the portal of the Tunnel[1]. As shown in Figure 1, the heated block of the SHT is bounded by the Observation Drift, Thermal-Mechanical Alcove, and Thermal-Mechanical Alcove Extension. The test region was characterized by Lawrence Berkeley National Laboratory (LBNL). They found that the average initial saturation level in the pore volume of the rock mass was about $92 \%$. They also found that the gas permeability within the block was not homogeneous, and ranges from $5 \times 10^{-15}$ to $5 \times 10^{-12} \mathrm{~m}^{2[2]}$. One single electrical heater element was placed in a heater hole which was drilled horizontally into the heated block, at about the middle of the Thermal-Mechanical Alcove at about $1.5 \mathrm{~m}$ from the floor. The heater element is about $5 \mathrm{~m}$ in length. The heated portion of the heater hole starts at about $2 \mathrm{~m}$ from its collar. The total power output of the heater is about $4 \mathrm{~kW}$. Figure 1 also shows the borehole layout in the SHT. Borehole $\# 1$ is the heater hole; \#2 to 4,8 to 14,19 , and 28 to 41 are for thermal-mechanical studies conducted by Sandia National Laboratory (SNL). In addition, the following holes are for testing the coupled TMHC processes: \#15, 17, 22, and 23 are for measuring temperature using resistance temperature devices (RTD), and neutron logging to map moisture distribution; \#16 and 18 are for measurement of relative humidity, gas pressure, and testing waste package material and introduced materials; \#20 and 21 are for measuring concentration of chemical species (including $\mathrm{pH}$, chloride, sulfide, dissolved oxygen, potassium, calcium, sodium, oxidation/reduction potential, and corrosion potential) and fluid extraction; \#24 to 27 are for using electrical resistivity tomography (ERT) to image 2-dimensional moisture distribution; and \#6 and 7 are for measuring the displacement of the rock mass along the holes using laser (optical) extensometers. All of these holes are about $7.5 \mathrm{~cm}$ in diameter, and their total depths are shown roughly in Fig. 1. Because the primary objective of the SHT is to determine the thermal-mechanical responses of the heated block, the orientation, location, and total length of the TMHC holes were adjusted so that they do 
not impair the construction of the thermal-mechanical holes. The $x, y$, and $z$ of the bottoms of these TMHC holes are listed in Table 1. The construction of each type of the TMHC holes is described below.

Table 1. $x, y$, and $z$ of the Bottoms of the TMHC Holes. The Collar of the Heater Hole is $(0,0,0)$

\begin{tabular}{|c|c|c|c|}
\hline Hole \# & $x(m)$ & $y(m)$ & $\mathrm{z}(\mathrm{m})$ \\
\hline 6 & 1.212 & 11.987 & 0.130 \\
\hline 7 & 0.298 & 6.445 & -0.268 \\
\hline 15 & -1.602 & 4.280 & 2.745 \\
\hline 16 & 1.136 & 4.324 & 0.709 \\
\hline 17 & -1.780 & 4.310 & -1.469 \\
\hline 18 & 1.511 & 4.280 & -0.283 \\
\hline 20 & -1.506 & 4.931 & -0.765 \\
\hline 21 & -1.059 & 5.097 & 0.626 \\
\hline 22 & -1.557 & 4.393 & -0.739 \\
\hline 23 & -1.312 & 4.420 & 0.648 \\
\hline 24 & -0.411 & 3.822 & 6.279 \\
\hline 25 & -0.292 & 4.074 & -6.216 \\
\hline 26 & 1.150 & 3.850 & -5.714 \\
\hline 27 & 0.383 & 3.973 & 6.286 \\
\hline
\end{tabular}

The RTD/neutron logging holes (\#15, 17, 22, and 23) consist of one liner and RTD bundle. The liner is made of Teflon tubes with an inner diameter slightly greater than $3.81 \mathrm{~cm}$, and a wall thickness of about $0.32 \mathrm{~cm}$. The first RTD in each bundle was placed as close to the bottom of the borehole as possible. The diameter of the neutron logging tool to be used in this test is about 3.81 $\mathrm{cm}$. RTD's are bundled on the outer surface of the Teflon tube with a spacing of about $30 \mathrm{~cm}$ along the longitudinal axis of the tube. The first RTD in each bundle was placed as close to the bottom of the borehole as possible. As mentioned earlier, in order to avoid interference with the thermal-mechanical holes the RTD/neutron logging holes were not placed at locations as close to the heater as we would prefer. Centralizers were mounted on the tube to keep the liner at about the center of each hole. The annular space between the liner and the hole was sealed with cement grout.

The chemical holes (\#20 and 21) consist of one $7.62 \mathrm{~cm}$ diameter Science Engineering Associates Membrane Insitu Sampling Technology (SEAMIST) membrane with chemical sensor pads mounted on its surface, and one $5.08 \mathrm{~cm}$ diameter SEAMIST membrane with absorbing pads 
mounted on its surface. Five chemical sensor pads were mounted on the $7.62 \mathrm{~cm}$ SEAMIST. The chemical sensor pads were placed at location of intersection of fractures with the holes, as determined by video images. Eight micro-electrode array chemical sensors were mounted in each chemical sensor pad. Those sensors measure $\mathrm{pH}$, oxidation/reduction potential, corrosion potential, and concentration of $\mathrm{Na}, \mathrm{Ca}, \mathrm{K}, \mathrm{S}, \mathrm{Cl}$, and dissolved oxygen. Five water absorbing pads were mounted on the $5.02 \mathrm{~cm}$ SEAMIST at the same location as the chemical sensor pads. Electrical resistance is measured in each absorbing pad to indicate the wetness in it. When the measured resistance indicates that the pads reach a greatest level of wetness, the pads will be removed from the holes to extract the fluid for chemical analyses. The SEAMISTs are inflated to seal the holes during the test.

Packers rated for the expected temperatures in the rock mass were installed in the hydrological holes (\#16 and 18). Due to constraints of borehole size, budget, and schedule, one 4-packer system was installed in each hydrological hole. Instruments to measure relative humidity, temperature, and gas phase pressure, and coupons of candidate waste package material and introduced material were mounted in the sections of the holes isolated by the packers. In order to seal a highly fractured portion near the collar of each hole, the outer packer in each packer system was placed within a short distance from the collar (14 cm for \#16, and $23 \mathrm{~cm}$ for \#18). Injection lines were installed in the packer system so that gas injection to determine hydrological properties, such as permeability, can be determined during the test. The packers are inflated during the test to seal the holes.

Electrodes for electrical resistivity tomography (ERT) were installed in the ERT holes (\# 24 27). The electrode spacing is $30 \mathrm{~cm}$. The electrodes were grouted in the holes. The cement grout was used to seal the holes and to improve the electrical contact between the electrodes and the rock mass.

Optical multiple point borehole extensometers (OMPBX) were installed in holes \#6 and 7. A laser is used to measure the distance between anchors in the OMPBX. Two anchors were installed in each hole. The OMPBX will measure the displacement of the rock mass between the two anchors in each hole. As shown in Fig. 1, Hole \#6 is for measuring the displacement along the heater, and hole \#7 is for measuring the displacement perpendicular to the heater.

\section{Test Procedures}

One of the objectives of the coupled TMHC test is to determine the effect of heating on the hydrological, chemical, and mechanical processes in the rock mass. Therefore the baseline data before the heater is energized are integral parts of the test. It would be ideal that the ambient data be taken for at least two weeks to one month. However, due to a pre-set schedule of turning on the heater only one set of the ambient ERT and one set of the neutron data were taken, and the 
ambient temperature, chemical, hydrological, and mechanical data were obtained for only a few days. The heater was energized to a full power of about $4 \mathrm{~kW}$ since August 26, 1996. The fullpower heating will continue for at least 9 months, then if enough data during the heating phase have been obtained the heater will be turned off to start a cool-down phase. Within the first month of heating ERT and neutron logging were conducted about twice per month. Thereafter they have been conducted once per month. Temperature data using RTD, hydrological data (relative humidity and temperature from Humicaps, and gas pressure), and readings from the chemical sensors have been acquired every hour. The electrical resistance of the absorbing pads in the chemical holes has been measured occasionally. . The displacement in the rock mass has been measured occasionally using the OMPBX. During the cool-down phase the data acquisition will be the same as during the heating phase. When the temperature in the rock mass decreases to about $5^{\circ} \mathrm{C}$ above the ambient temperature, the rock mass is considered to be cooled and at least one set of the post-test data will be collected. Then the packers in the hydrological holes will be removed and the candidate waste package material coupons and the introduced material coupons will be examined for evidence of any changes during the test. Overcoring of some of the holes to obtain core samples for determining changes in mineralogy/petrology that may occur due to rock-water interactions during the test. This paper reports data of the pre-heat phase and during the heating phase up to January 30, 1997.

The SHT Results and Discussion

As mentioned above, the SHT is on-going; therefore, the results presented in this progress report are far from being complete. The analyses and interpretation of the test results are preliminary. The SHT results will be presented according to measurement types first, and an integrated discussion will be presented at the end of this section.

\section{Temperature Measurements}

Temperature in the rock mass is measured by RTD in Holes \#15, 17, 22, and 23. All of these holes were drilled perpendicular to the heater hole, at about the middle of the heated section (about $4.5 \mathrm{~m}$ from the collar of the heater hole (Hole \#1). SNL also measures the temperature in Holes \#8 to 14 using thermocouples. Among the SNL thermocouple holes, Holes \#8 to 12 were drilled parallel to the heater hole, at various distances from it; Holes \#13 and 14 were drilled perpendicular to the heater hole. Temperature is also measured by thermocouples in the SNL MPBX holes, Holes \#2 to 5. However, because the SNL MPBX holes are not sealed (not grouted), the temperature measured in those holes may be affected by the un-sealed borehole. Therefore the temperature results in the MPBX holes are not considered in the analysis.

Figure 2 shows the temperatures and neutron counts along the RTD holes (Holes \#15, 17, 22, and 23) on January 30, 1997. The temperatures in these holes agree well with those in the SNL 
thermocouple holes which are perpendicular to the heater hole (Holes \#13 and 14). The temperatures in those RTD holes are all below $100^{\circ} \mathrm{C}$, which is the boiling point of water at standard conditions, because those holes were not drilled close enough to the heater hole. The temperature data in Hole \#13 indicates that the temperature within a region about $0.7-0.8 \mathrm{~m}$ in radius from the heater was above $100^{\circ} \mathrm{C}$ on this day of heating.

\section{Chemical Measurements}

The data from the chemical sensors in Holes \#20 and 21 have been acquired since August 22 , 1996 , about 5 days before the heater was energized. The sensor output is supposed to be in the range of milivolts. However, the measured outputs of the sensors have been either beyond the range of calibration or very noisy. No trend of the variation of the sensor output with respect to the test procedures, such as energizing the heater and heating of the rock mass, has been established. The measured results seem to indicate that the sensors are in relatively dry environments. Attempts were made to wet the sensors, but without much success in changing their outputs. A spare sensor pad was tested in the laboratory by submerging it in water solutions of known levels of concentration of certain chemical species, such as $\mathrm{Cl}, \mathrm{Na}, \mathrm{K}$, etc. The output of the testing sensors were within the expected range, but the calibration results did not agree with that provided by the manufacturer. In addition, the voltage output of a sensor due to the concentration of a certain ion seems to be dependent of the presence of other chemicals in the same solution. Based on the calibration and laboratory tests we concluded that the micro-electrode array chemical sensors are not suitable for in situ measurement of concentration of chemical species in the originally partially saturated rock.

On November 25, 1996 about 5.5 liter of water was collected from one of the packed-off sections in Hole \#16. This packed-off section is about $2.13 \mathrm{~m}$ in length, and is the section closest to the heater in this hole. This hole was drilled from the Thermal-Mechanical Alcove Extension toward the heater with a 7.5 degree inclination (Fig. 1). The water may have been driven away from the heater hole by the heat, and flowed through fractures that intersect with that $2.13-\mathrm{m}$ section of the hole. The bromine content of the water is much less than that in the drilling fluid, indicating that the collected water was not contaminated by the drilling fluid. The collected water is chemically more dilute than the ground water at J-13 well (J-13 water), except for the concentration of $\mathrm{Ca}$, which is the same as in J-13 water [3]. This indicates that the collected water was condensed from vapor, and had flowed through fractures before it reached Hole \#16. The water had not reached chemical equilibrium with the rock mass, except with the carbonate minerals on the fracture surfaces. More detailed chemical analyses will be performed on the water.

The absorbing pads in Hole \#21 were removed from the hole on January 8, 1997. Four out of the five pads seem to have absorbed significant amounts of water. The fluid in the absorbing pads 
will be analyzed later. The chemicals in the water from various pads will provide information about the variation of the water chemistry as a function of distance from the heater.

\section{Hydrological Measurements}

Relative humidity and temperature are measured by Humicaps, and gas phase pressure is measured by pressure transducers in Holes \#16 and 18. The measurements were started on August 22, 1996. The temperature measured by the Humicaps agrees well with that measured by RTD and thermocouples. Figure 3 shows the relative humidity in Hole \#18 as a function of time. The 0 day is when the heater was energized. The results in Hole \#16 are similar to those in Hole \#18. Sensor No. 1 in Hole \#18 is near the collar of the hole; sensor No. 4 is the closest one to the heater hole. Sensor No. 4 is within a section of the hole of about $1.72 \mathrm{~m}$ in length; all of the other sensors are in sections of the hole of only about $6.35 \mathrm{~cm}$ in length. The relative humidity within section 4 (Sensor No. 4) decreased for several days since the heater was energized, then increased to about $100 \%$, and has remained at that level since. This is what we would expect, based on laboratory results that less than $50 \%$ saturation in the rock matrix would be enough to cause the relative humidity to reach $100 \%$ [4]. However, the relative humidity in other sections of the hole decreased with time to around $86-90 \%$, then increased. The reason is not clear yet. One possible explanation is that those sections of the hole had episodic communication with the open air in the alcoves, either through fractures or through the packers.

The gas pressures in this hole are shown in Figure 4. The gas phase pressure in sections 1 - 3 have been slightly below the atmospheric pressure in the alcoves and slightly decreasing with time. In section 4 however, the gas pressure is greater than the atmospheric pressure and remains constant. The positive gauge pressure in section 4 may be due to the increase in vapor pressure; the negative gauge pressures in other sections may be due to condensation. The gas pressures in Hole \#16 are more complicated: the pressure in sections 1, 3, and 4 are all negative; it is positive in section 2.

\section{Thermal Mechanical Measurements}

Optical MPBX were installed in Holes \#6 and 7. Two anchors/reflectors were installed in each hole. A reference for the distance measurement was installed at the collar of each hole. A fracture near the collar of Hole \#6 caused a slice of rock about $15 \mathrm{~cm}$ thick at the collar of the hole to slide downward. This sliding made Hole \#6 useless for the OMPBX measurement. Figure 5 shows the result of the OMPBX in Hole \#7 as a function of time. This result indicates that the rock mass between the two anchors has been expanding since the heater was energized. This is in agreement with the preliminary results from the SNL MPBX sensors in Hole \#5, in which the outer anchors showed expansion in the direction perpendicular to the heater since the heating. 
However, displacement measurements by the SNL MPBX in the direction parallel to the heaters show variable results (expansion and contraction) in various locations from the heater.

\section{Water Content Measurements}

Two methods are used in the SHT to determine the spatial and temporal variations of the moisture content in the rock mass. They are neutron logging to determine the water content along boreholes, and ERT to determine the distribution of moisture content in two-dimensional planes. The neutron logging is conducted in Holes \#15, 17, 22, and 23 (in the same holes as the RTD for measuring temperature). The ERT is conducted in Holes $\# 24$ to 27, as shown in Fig. 1.

Because the neutron tool has not been calibrated for the current borehole/liner configuration yet, therefore the neutron counts are presented in here. Although the neutron counts do not show quantitative moisture content, they offer the same information of drying and wetting. Figure 2 shows the delta of smoothed neutron counts (the current minus the pre-heat). The neutron counts are smoothed using a five-point smoothing window, then the pre-heat smoothed counts (measured on August 21, 1996) were subtracted from the current counts (measured on January 30, 1997). The zero on the vertical axis in Fig. 6 means no change; positive values mean wetter; and negative values mean drier. In general the drying and wetting along those holes agree with the temperature distributions, as shown in Fig. 2. Fractures as recorded by video imaging are shown in Holes \#22 and 23. No fracture data are available in Holes \#15 and 17. Wetting and drying in Holes \#22 and 23 seem unrelated to the fracture distributions. The big drying at the 5-m depth from the collar of Hole \#17 will be analyzed further when fracture information is available.

Figure 6 shows the ERT image of the rock mass encompassed by Holes \#24 to 27, as taken on October 25, 1997. The images shown in this figure are the ratio of resistivity on 10/25/96 to that on $8 / 22 / 96$, the pre-heat data. Figure 6 shows that the resistivity ratio decreases from 1.0 (means no change) at the boundary of the imaged region to about 0.5 near the heater region. Also shown in Fig. 6 are circles approximating the temperatures as measured on October 23, 1996. A decrease in resistivity in this case may be due to both increase in moisture content and increase in temperature, as reported by Roberts and Lin [5]. The temperature information shown above will be combined with the laboratory determined relationship between resistivity and temperature in the Topopah Spring tuff so that the temperature effect on the resistivity can be removed from the ERT images. Then the variation in moisture content can be calculated based on the ERT results. When this is done we expect to see a small region near the heater where the water saturation level may be much less than the initial saturation level in the rock mass, i.e. a dry-out region. This is consistent with the neutron logging results.

In summary, the preliminary results of the coupled TMHC responses of the heated rock mass indicate that the heat did move the moisture about the heater hole. As mentioned above, the 
primary purpose of the SHT is for testing thermal-mechanical responses of the rock mass. In order to avoid interference with the thermal-mechanical holes, the boreholes for the coupled TMHC processes were not located near the heater hole. So far a small dry-out region may have been created around the heater. The water that has been relocated by the heat is more diluted than the J13 water, and may have only reached chemical equilibrium with the secondary minerals on the fracture surfaces. The thermal-mechanical measurement results are not conclusive enough for assessing thermal-mechanical-hydrological couplings. A complete analysis of the data will be conducted when the heating phase of the test is completed.

\section{References}

[1] Civilian Radioactive Waste Management System Management \& Operation Contractor, 1996, Test design, Plans and Layout for the ESF Thermal Test, BAB000000-01717-4600-00025 REV 01, TRW Environmental Safety Systems Inc., 101 Convention Center Drive, Las Vegas, NV 89109.

[2] Civilian Radioactive Waste Management System Management \& Operation Contractor, 1996, Characterization of the ESF Thermal Test Area, B00000000-01717-5705-00047 REV 01, TRW Environmental Safety Systems Inc., 101 Convention Center Drive, Las Vegas, NV 89109.

[3] Harrar, J., Carley, J.F., Isherwood, W.F., and Raber, E., 1990, Report of the committee to review the use of J-13 water in Nevada Nuclear Waste Storage Investigations, Lawrence Livermore National Laboratory, UCID-21867, Livermore, CA.

[4] Lin, W., Roberts, J., and Ruddle, D., 1996, "Relative humidity in the near-field environment," Proceedings of the Seventh Annual International Conference on High Level Radioactive Waste Management, Las Vegas, NV, April 29 - May 3, 1996, American Nuclear Society, Inc., La Grange Park, IL 60525, pp. 128-129.

[5] Roberts, J. and Lin, W., 1997, "Electrical properties of partially saturated Topopah Spring tuff: water distribution as a function of saturation," Water Resource Researches, American Geophysical Union, Washington, DC, In press 
Acknowledgment

P. Berge reviewed this paper. Her comments improved the manuscripts greatly. This work is performed under the auspices of the U.S. Department of Energy by Lawrence Livermore National Laboratory under contract W-7405-ENG-48. This work is supported by Yucca Mountain Site Characterization Project, LLNL. 


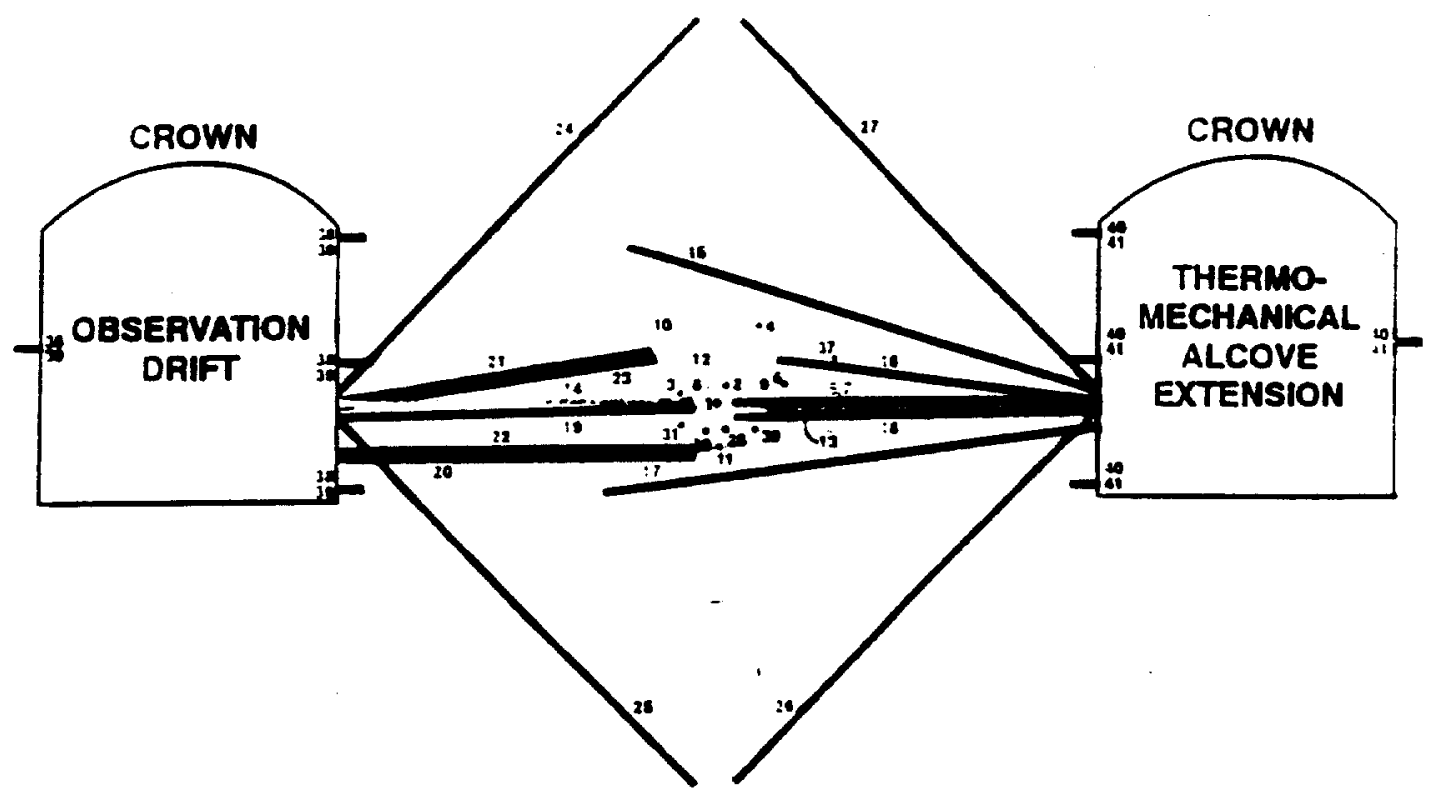

CROSS-SECTION A-A

THERMOMECHANICAL

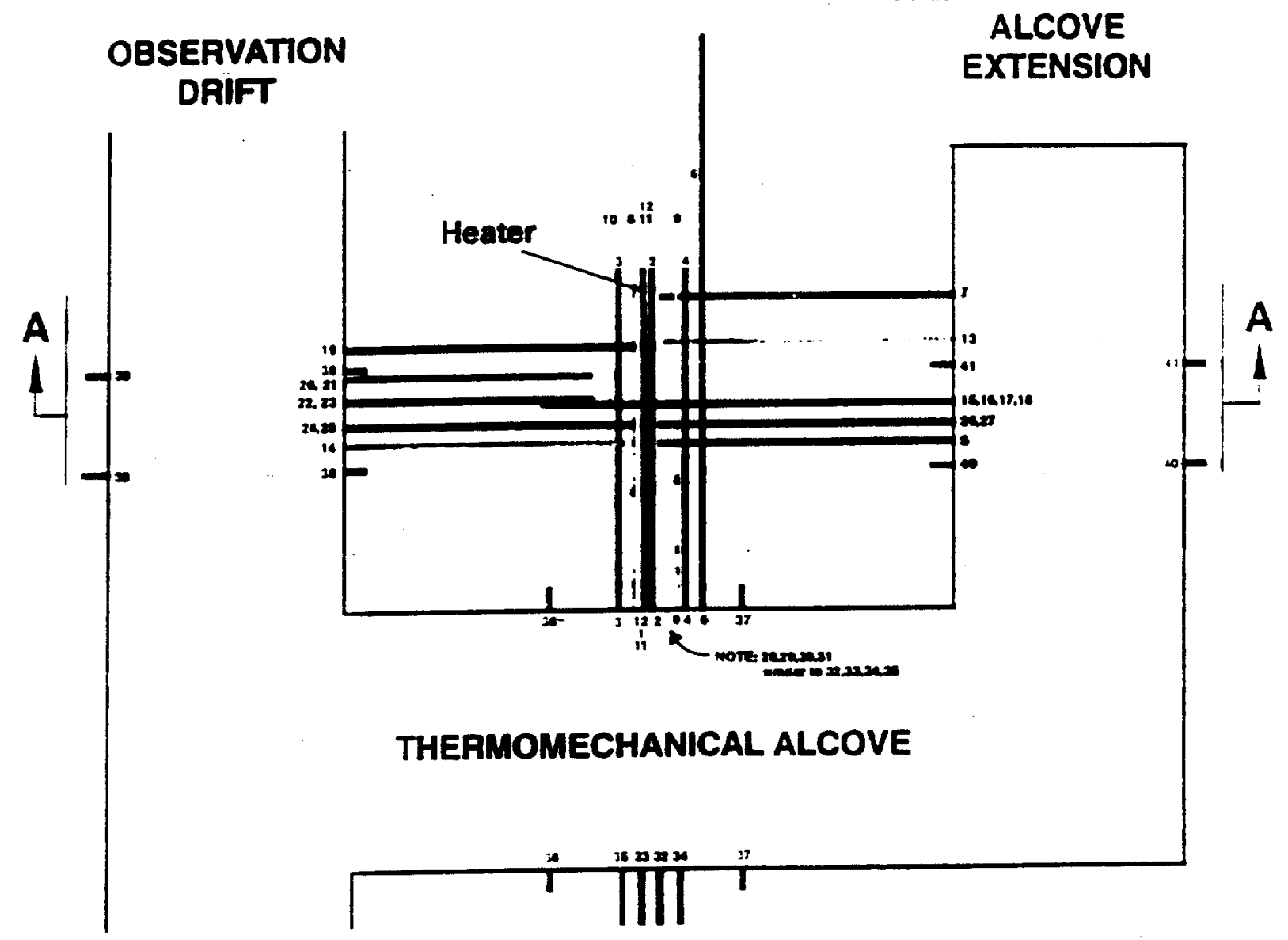

- Figure 1. Borehole layout of the Single Heater Test. 

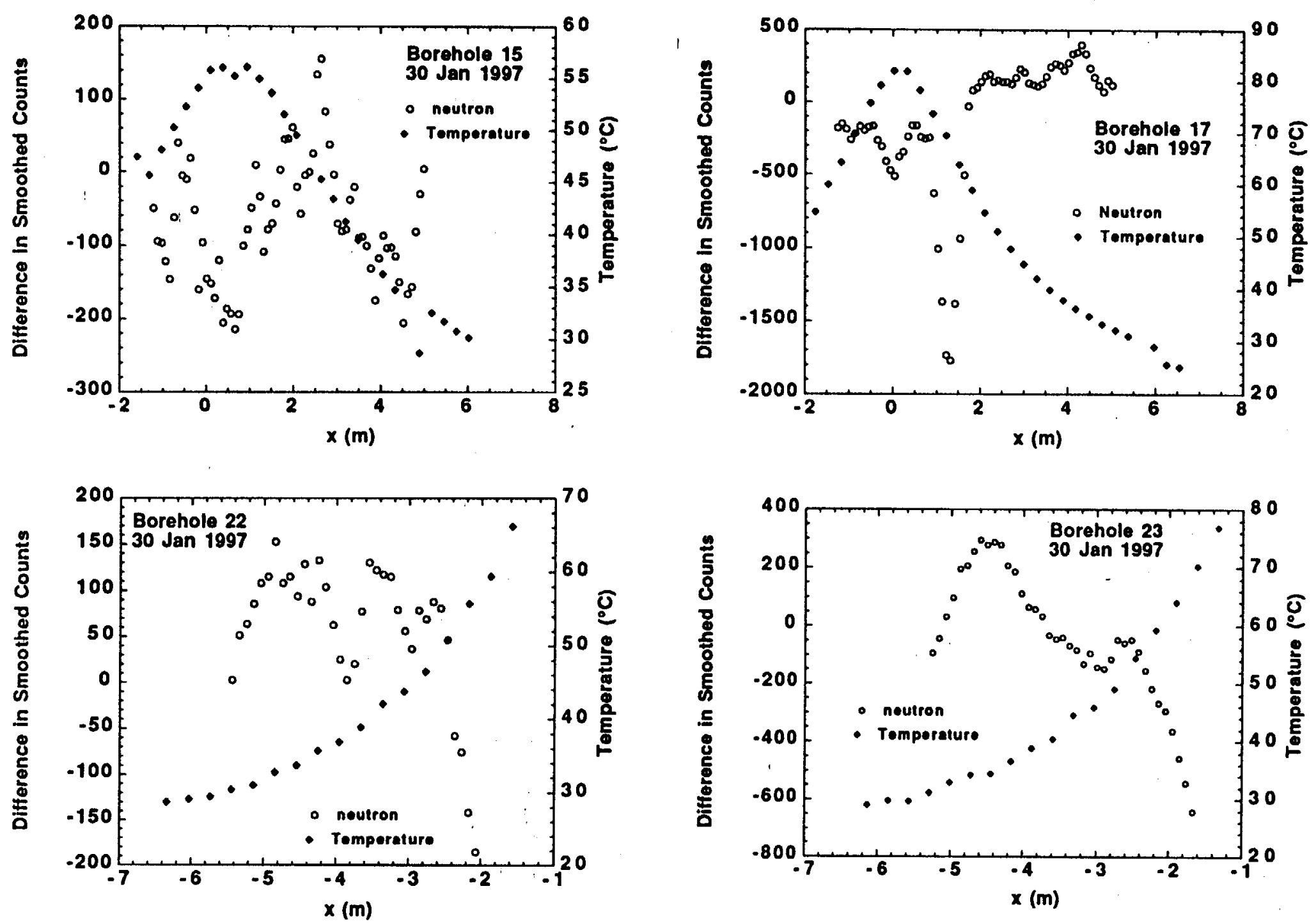

Figure 2. Temperature and neutron data as a function of $x$ in Holes $15,17,22$, and 23 . The neutron data are difference of smoothed counts. 

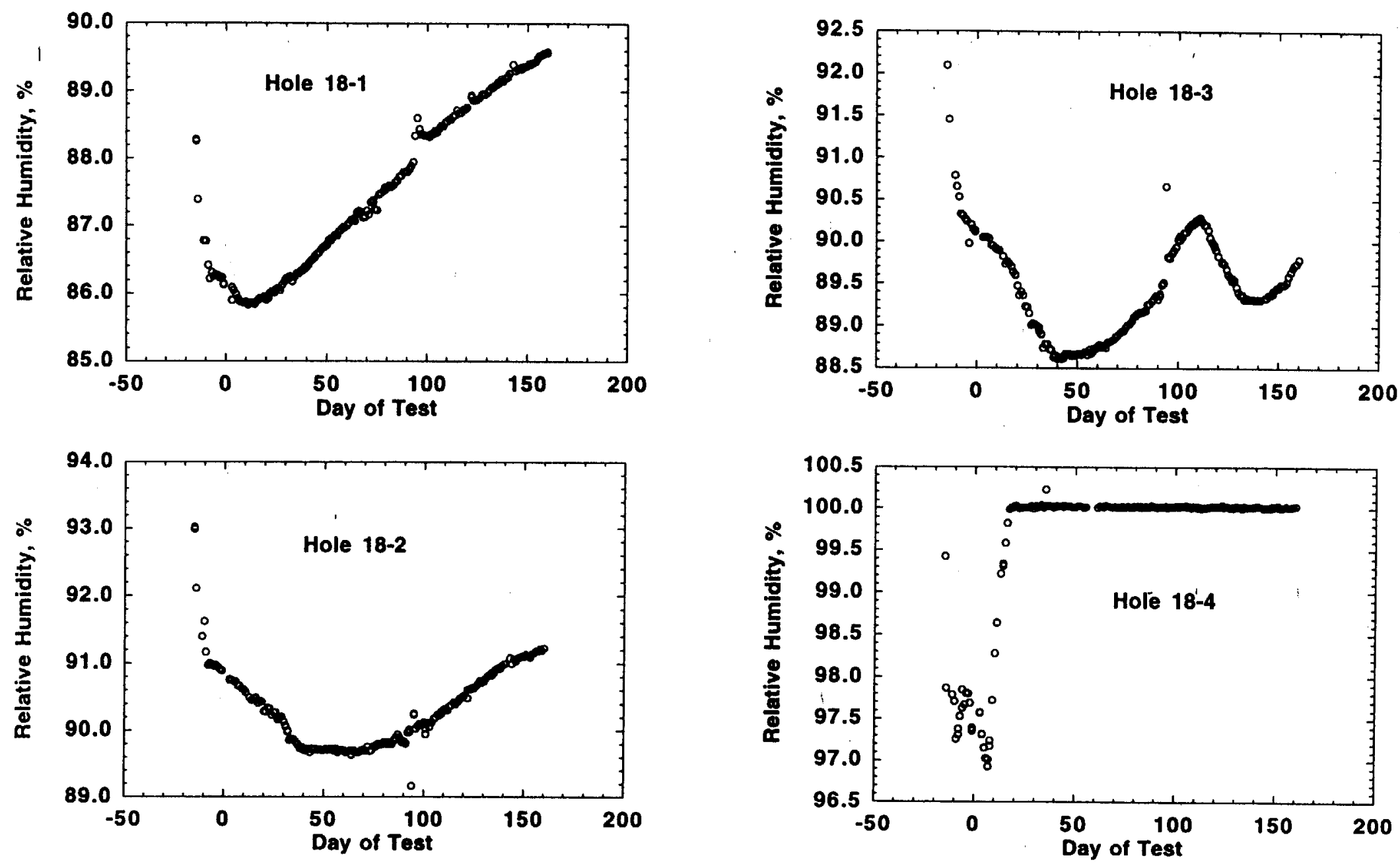

Figure 3. Relative humidity in four zones of Borehole 18 as a function of day of test. 

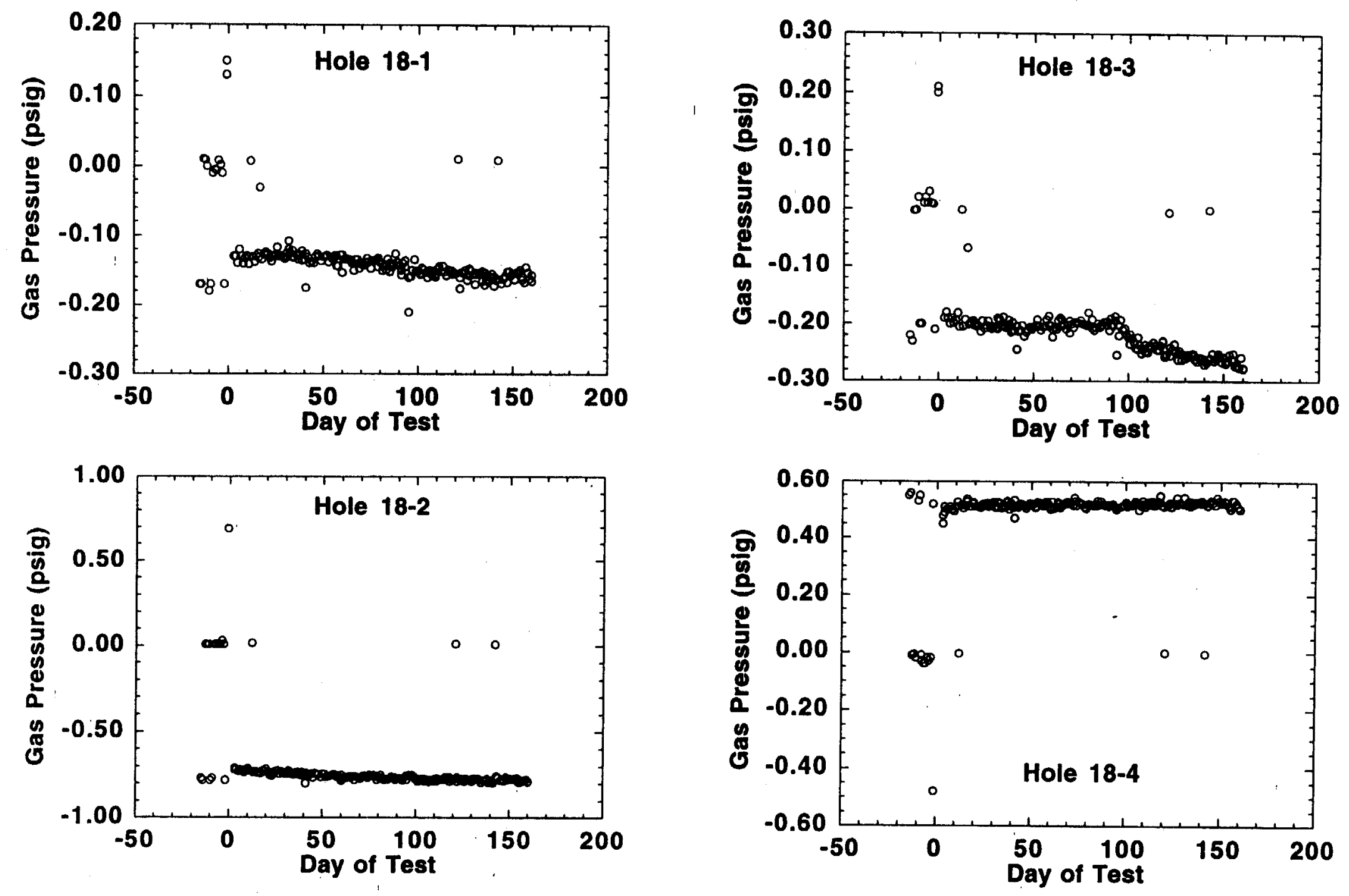

Figure 4. Gauge gas pressure in four zones of Borehole 18 as a function of day of test. 


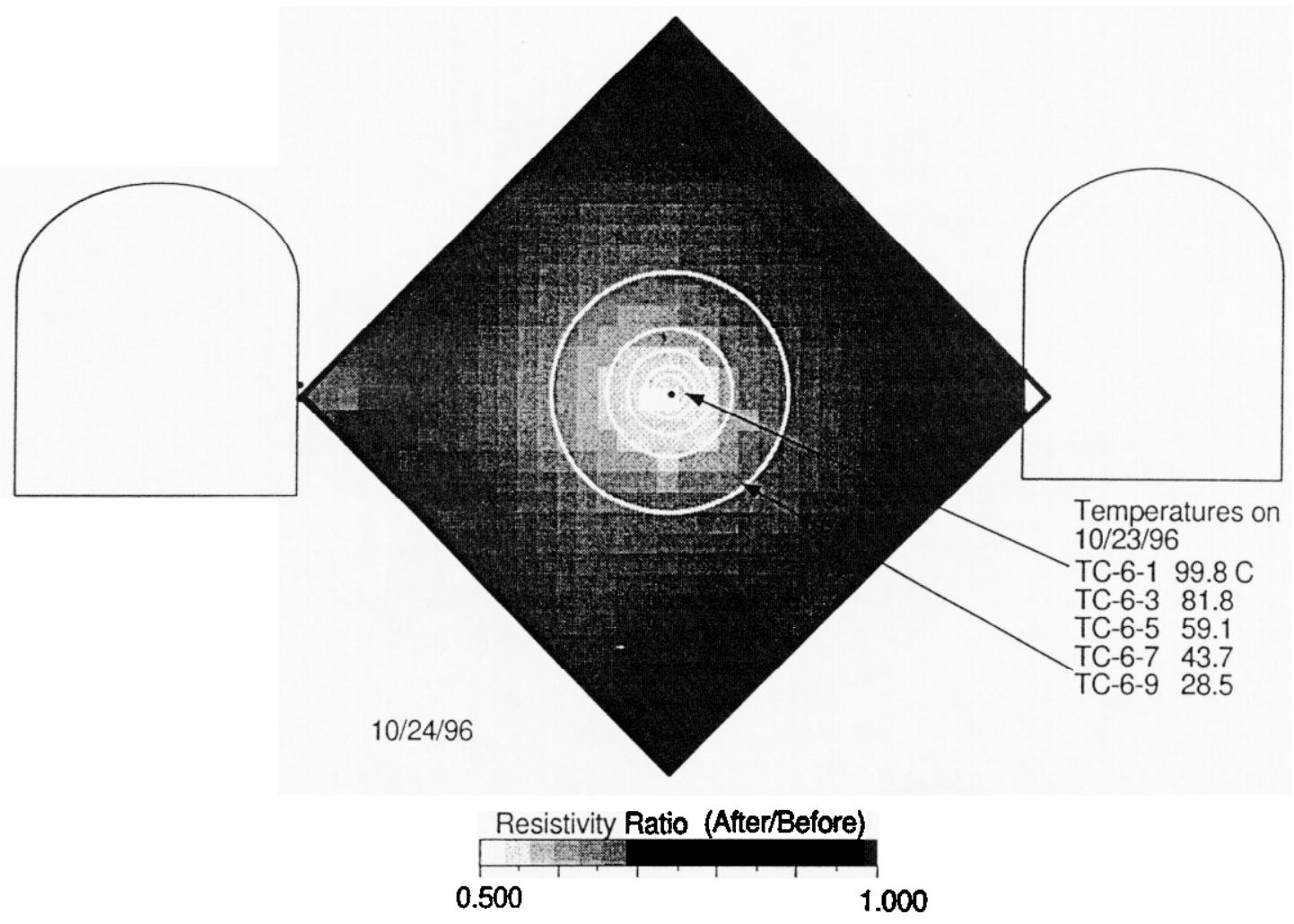

Figure 5. ERT image of the Single Heater Test on October 24, 1996. The resistivity ratio is with respect to the pre-heat data on August 22, 1996. 


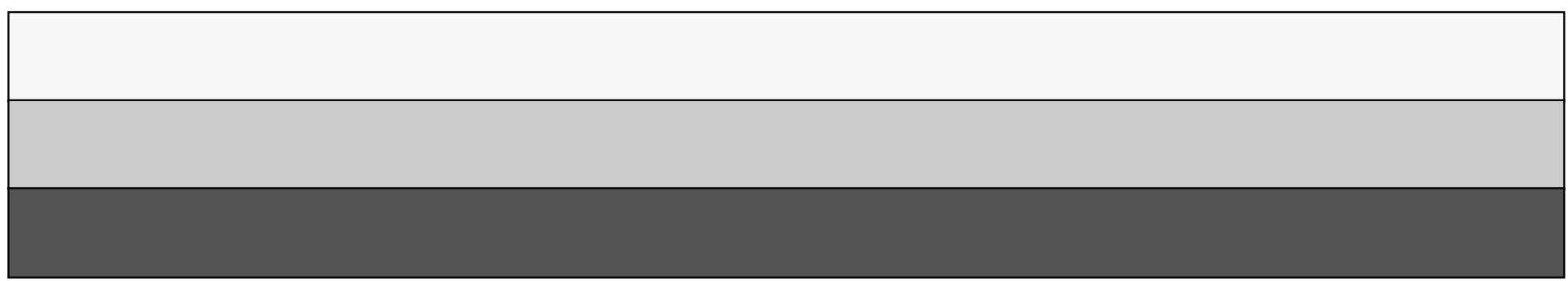

